\title{
Analisis Penerapan Total Productive Maintenance (TPM) dengan Metode Overall Equipment Effectiveness (OEE) pada Mesin Kneader (Studi Kasus PT. XYZ)
}

\author{
Muhamad Ruslan ${ }^{1}$, Alloysius Vendhi Prasmoro ${ }^{* 2}$ \\ Teknik Industri Fakultas Teknik, Universitas Bhayangkara Jakarta \\ e-mail: ${ }^{1}$ mruslan266@gmail.com,${ }^{2}$ alloysius.vendhi@dsn.ubharajaya.ac.id
}

\begin{abstract}
PT. XYZ has implemented Total Productive Maintenance (TPM) to improve the efficiency and effectiveness of manufacturing companies as a whole. However, the implementation is still not optimal and seen from not achieving the production target. This study aims to measure the value of the effectiveness of equipment, find the root causes of problems and provide suggestions for improvement. The study was conducted on a kneader machine that had the highest breakdown rate. This research begins by measuring the overall equipment effectiveness (OEE) achievement value, then identifying the six big losses that occur. The results showed that the average OEE value on the kneader machine was $81.62 \%$, the effectiveness value was classified as very low because the standard OEE value for world-class companies was ideally $85 \%$. The biggest factor influencing the low OEE value is the performance rate with a factor of six big losses in reducing spees losses of $42.66 \%$ and idling and minor stoppages of $31.27 \%$ of all time losses. What causes the magnitude of losses consists of human, machine, material, method, and environmental factors. Human and machine factors are the most dominant factors. To reduce these losses, companies should provide skills and knowledge training to operators about the signs of damage to the equipment. In addition, operators are given additional work in the form of equipment maintenance that is often used in work so that maintenance work can be more focused. Then the company must pay more attention to the comfort of the operator at work so that fatigue can be reduced and operator productivity is increased and increase operator awareness of the tools they use.
\end{abstract}

Keywords: Overall Equipment Effectiveness (OEE), Six Big Losses, Idling and Minor Stoppages

\section{ABSTRAK}

PT. XYZ telah menerapkan Total Productive Maintenance (TPM) guna meningkatkan efisiensi dan efektivitas perusahaan manufaktur secara menyeluruh. Namun dalam pelaksanaannya masih belum optimal dan dilihat dari tidak tercapainya target produksi. Penelitian ini bertujuan untuk mengukur nilai efektivitas peralatan, mencari akar penyebab masalah dan memberikan usulan perbaikan. Penelitian dilakukan pada mesin kneader yang selama ini memiliki tingkat breakdown yang tertinggi. Penelitian ini dimulai dengan mengukur pencapaian nilai overall equipment effectiveness (OEE), kemudian mengidentifikasi six big losses yang terjadi. Hasil penelitian menunjukan bahwa rata-rata nilai OEE pada mesin kneader sebesar 81,62\%, nilai efektivitas ini tergolong sangat rendah karena standar nilai OEE untuk perusahaan kelas dunia idealnya adalah $85 \%$. Faktor terbesar yang mempengaruhi rendahnya nilai OEE adalah performance rate dengan faktor persentase six big losses pada reduce spees losses $42,66 \%$ dan idling and minor stoppages sebesar 31,27\% dari seluruh time losses. Yang menyebabkan besarnya losses terdiri dari faktor manusia, mesin, material, metode, dan lingkungan. Faktor manusia dan mesin merupakan faktor yang paling dominan. Untuk mengurangi kerugian tersebut, perusahaan sebaiknya memberikan pelatihan skill dan pengetahuan kepada operator tentang tanda-tanda kerusakan alat tersebut. Selain itu operator diberikan tambahan pekerjaan berupa perawatan peralatan yang sering digunakannya dalam bekerja sehingga pekerjaan bagian 
maintenance bisa lebih berfokus. Kemudian perusahaan harus lebih memperhatikan kenyamanan operator dalam bekerja sehingga kelelahan bisa dikurangi dan produktivitas operator lebih meningkat serta meningkatkan kepedulian operator terhadap alat yang digunakannya.

Kata kunci: Overall Equipment Effectiveness (OEE), Six Big Losses, Idling and Minor Stoppages.

\section{PENDAHULUAN}

Perkembangan industri dan teknologi dalam era globalisasi sekarang ini semakin pesat, ditandai dengan tingkat persaingan antara perusahaan yang semakin meningkat dan ketat. Keadaan ini menyebabkan perusahaan harus mampu bersaing mempertahankan usaha yang dikelolanya. Salah satu hal yang mendukung kelancaran kegiatan operasional dalam suatu perusahaan adalah mesin-mesin produksi harus dalam kondisi siap pakai untuk melaksanakan tugasnya. Untuk menjaga agar mesin-mesin produksi mampu beroperasi ataupun berfungsi sebagaimana mestinya maka dibutuhkan perawatan mesin yang baik. Perawatan mesin yang baik sangat penting untuk mencapai kinerja yang efektif dan efisien dalam suatu sistem. Untuk itu diperlukan adanya penjadwalan pemeliharaan mesin yang baik agar mencapai tujuan perusahaan yaitu dapat memproduksi dengan efektif dan efisien, memenuhi permintaan pasar, memberikan kepuasan pada konsumen serta memperoleh keuntungan yang tinggi.

PT. XYZ adalah perusahaan yang bergerak di bidang produksi lead pencil. Perusahaan yang terletak di kota Bekasi Jawa Barat ini menempati lahan seluas $10.000 \mathrm{~m}^{\wedge} 2$ dengan luas bangunan $7.381 \mathrm{~m}^{\wedge} 2$ hingga 4.000 .000 gross/tahun. Produk yang dihasilkan berupa lead pensil. Untuk menghasilkan produk tersebut perusahaan menggunakan beberapa mesin yaitu mesin mixer, mesin extruder, mesin dryer, mesin centrifuge, mesin equalizing, mesin kneader, dan beberapa mesin pendukung lainnya. Kerusakan mesin tidak bisa dihindarkan apabila waktu pemakaian mesin tersebut melebihi kapasitas dan sistem perawatannya tidak baik. Mesin dan peralatan mendapatkan penanganan setelah mengalami kerusakan (corrective maintenance) tanpa memperhatikan faktor keandalan dari komponen mesin-mesin produksi. Kerusakan mesin yang terjadi mengakibatkantertundanyaproses produksi karena mesin tidak dapat berfungsi baik.

Salah satu mesin yang diĝnakan dalam produksinya yaitu, mesin kneader. Mesin yang digunakan terus menerus akan mempengaruhi performa mesin itu sendiri, maka dari itu PT.XYZ membutuhkan sistem pemeliharaan mesin yang baik agar mesin tidak mengalami kerusakan yang akhirnya akan menggangu proses produksinya. Saat ini perusahaan sudah menerapkan preventive maintenance namun breakdown mesin masih sering terjadi.

Tabel 1 Jumlah kerusakan mesin kneader Jan-Jun 2018

\begin{tabular}{lcccccc}
\hline Bulan & Jan & Feb & Mar & Apr & Mei & Jun \\
\hline $\begin{array}{l}\text { Kerusak } \\
\text { an mesin }\end{array}$ & 6 & 8 & 7 & 10 & 5 & 4 \\
$\begin{array}{l}\text { kneader } \\
\text { (jam) }\end{array}$ & & & & & & \\
\hline
\end{tabular}

Sumber: Data Perusahaan (2018)

Dengan permasalahan tersebut maka perlu dilakukan perbaikan proses maintenance. Untuk itu penulis tertarik untuk menganalisis mengenai Total Preventive Maintenace yang hasilkan dapat disajikan dalam penelitian yang berjudul "Analisis Penerapan Total Productive Maintenance (TPM) dengan Metode Overall Equipment Effectiveness (OEE) pada Mesin Kneader (Studi Kasus PT. XYZ)" 


\section{METODE PENELITIAN}

\subsection{Pengertian Pemeliharaan}

Menurut Heizer dan Render (2010) pemeliharaan (maintenance) adalah mencakup semua aktivitas yang berkaitan dengan menjaga semua peralatan sistem agar tetap dapat bekerja. Sedangkan, Assauri (2008) berpendapat bahwa pemeliharaan adalah seluruh kegiatan yang mencakup upaya menjaga sistem peralatan, agar dapat bekerja sesuai harapan.

\subsection{Jenis Pemeliharaan}

Menurut Assauri (2008) dalam sistem pemeliharaan terdapat tiga jenis pemeliharaan, yaitu:

\section{1). Preventif Maintenance}

Yaitu kegiatan pemeliharaan dan perawatan yang dilakukan untuk mencegah timbulnya kerusakan-kerusakan yang tidak terduga dan menemukan kondisi atau keadaan yang dapat menyebabkan fasilitas produksi mengalami kerusakan pada waktu digunakan dalam proses produksi. Dalam praktiknya pemeliharaan preventif yang dilakukan oleh suatu perusahaan dapat dibedakan sebagai berikut:

a) Pemeliharaan rutin, yaitu aktivitas pemeliharaan dan perawatan yang dilakukan secara rutin (setiap hari). Misalnya pembersihan peralatan, pelumasan oli, dan lain-lain.

b) Pemeliharaan periodik, yaitu aktivitas pemeliharaan dan perawatan yang dilakukan secara periodik atau jangka waktu tertentu, misalnya setiap 100 jam kerja sekali, dan seterusnya.

\section{2). Corrective atau Breakdown} Maintenance

Yaitu kegiatan pemeliharaan dan perawatan yang dilakukan setelah terjadinya suatu kerusakan atau kelainan pada fasilitas atau peralatan sehingga tidak dapat berfungsi dengan baik.

\section{3). Predictive Maintenance}

Yaitu kegiatan perawatan yang bersifat prediksi, dalam hal ini merupakan evaluasi berkala (preventive maintenance).Pendekatan ini dievaluasi dan indikator-indikator yang terpasang pada instalasi suatu alat dan juga dapat melakukan pengecekan vibrasi dan alignment untuk menambah data dan tindakan dan perbaikan selanjutnya.

\subsection{Six Big Losses}

Menurut Nakajima (1988), terdapat 6 kerugian besar (six big losses) yang menyebabkan rendahnya nilai Overall Equipment Effectiveness (OEE) dan juga rendahnya kinerja peralatan. 6 kerugian ini terbagi menjadi 3 bagian yaitu terdiri dari:

\section{1).Downtime Losses}

Downtime losses adalah waktu yang seharusnya digunakan untuk kegiatan produksi, tapi terbuang karena mesin yang mengalami gangguan dan mengakibatkan tidak dapat menjalani kegiatan produksi sebagaimana mestinya.Downtime losses terdiri dari dua faktor, yaitu :

\section{a). Equipment Failure Losses (Breakdown)}

Kegagalan mesin melakukan proses atau kerusakan yang terjadi secara tiba-tiba, merupakan kerugian yang terlihat jelas, karena kendala tersebut, mesin yang beroperasi tidak menghasilkan output.

Berikut adalah rumus menghitung equipment failure losses:

$$
\begin{aligned}
& \text { Equipment Failure Losses }= \\
& \frac{\text { Total Breakdown Time }}{\text { Loading Time }} \times 100 \%
\end{aligned}
$$

\section{b). Set Up \& Adjustment Losses}

Kerusakan pada mesin atau pemeliharaan pada mesin, membuat mesin harus diberhentikan terlebih dahulu sebelum difungsikan kembali akan dilakukan penyesuaian terhadap fungsi mesin tersebut yang dinamakan dengan waktu set up \& adjustment losses. Dalam perhitungan, digunakan data set up mesin yang mengalami kerusakan dan pemeliharaan secara menyeluruh. 
Berikut adalah rumus menghitung set up and adjustment losses:

$$
\text { Set } U p \text { and Adjustment Losses }=
$$

$\frac{\text { Total set up Adjustment Time }}{\text { Loading Time }} \times 100 \%$

\section{2). Speed Losses}

Speed Losses terjadi pada saat kecepatan mesin mesin tidak beroperasi sesuai dengan kecepatan maksimum yang sesuai dengan kecepatan mesin yang dirancang. Speed Losses terdiri dari dua faktor, yaitu :

\section{a) Idling and Minor Stoppages Losses}

Idling and minor stoppages losses terjadi jika mesin berhenti secara berulang-ulang atau bisa juga mesin beroperasi tanpa menghasilkan produk. Jika hal ini sering terjadi, maka dapat mengurangi efektivitas mesin. Berikut adalah rumus menghitung Idling and Minor Stoppages :

Idling and Minor Stoppages $=$ $\frac{\text { Nonproduktive time }}{\text { Loding time }} \times 100 \%$

\section{b) Reduced Speed Losses}

Adalah selisih antara kecepatan waktu yang aktual dengan kecepatan waktu yang ideal. Berikut adalah rumus reduse speed losses:

Reduce speed losses $=$ $\frac{\text { total production-ideal production }}{\text { loading time }} \times 100 \%$

\section{3). Defect Losses}

Adalah keadaan mesin yang tidak menghasilkan produk yang sesuai dengan kualitas yang telah ditetapkan dan scrap sisa hasil produksi berjalan. Defect Losses terdiri dari dua faktor, yaitu :

\section{a) Rework Losses}

Adalah produk yang tidak memenuhi standard kualitas yang telah ditentukan walaupun masih dapat diperbaiki atau dikerjakan ulang.

Berikut adalah rumus rework losses :

56
Rework $=\frac{\text { Ideal cycle time } x \text { Rework }}{\text { Loading time }} \times 100 \%$

\section{b) Yield / Scrap Losses}

Adalah kerugian yang timbul selama proses produksi belum mencapai keadaan produksi yang belum stabil pada saat proses produksi mulai dilakukan sampai tercapainya keadaan proses yang stabil, sehingga produk yang dihasilkan dari awal proses sampai keadaan proses stabil dicapai tidak memenuhi spesifikasi kualitas yang diharapkan. Berikut adalah rumus yield/scrap losses:

$$
\begin{aligned}
& \text { Yield or Scrap Loss }= \\
& \frac{\text { Ideal cycle time } x \text { Scrap }}{\text { Loading time }} \times 100 \%
\end{aligned}
$$

\subsection{Total Productive Maintenance (TPM)}

Menurut Nakajima (1988), Total Productive Maintenance (TPM) adalah konsep program tentang pemeliharaan yang melibatkan seluruh pekerja melalui aktivitas kelompok kecil.

TPM pertama kali digagas di Jepang pada tahun 1971. Penggagas TPM pertama kali adalah Japanese Institute of Plant Maintenance (JIPM)

TPM memiliki tiga komponen, yaitu:

1) Pendekatan Total (Total Approach)

Filosofi dari TPM sesuai dengan semua aspek yang terkait dengan fasilitas yang dipergunakan dalam area operasi dan orang yang mengoperasikan, menset up dan merawat fasilitas yang merupakan objek yang menjadi fokus perhatian.

2) Aksi yang Produktif (Productive Action)

Pendekatan yang bersifat proaktif pada setiap kondisi dari operasi fasilitas bertujuan untuk meningkatkan produktifitas secara terus-menerus dan performansi bisnis yang optimal secara keseluruhan.

3).Perawatan (maintenance)

Metodologi yang sangat praktis untuk melakukan manajemen perawatan yang baik dan peningkatan keefektivitasan dari fasilitas 
dan integrasi dari semua operator produksi hingga level manajemen.

\subsection{Overall Equipment Effectiveness (OEE)}

Menurut Ansori dan Mustajib (2013), Overall Equipment Effectiveness (OEE) adalah metode yang digunakan sebagai alat ukur (metrik) dalam penerapan program TPM untuk menjaga peralatan tetap ideal dengan menghapus 6 six big losses peralatan. Selain itu, untuk mengukur suatu sistem kerja secara produktif dengan kemampuan mengidentifikasikan secara jelas akar suatu permasalahan dan faktor penyebabnya sehingga membuat usaha perbaikan menjadi terfokus merupakan faktor pertama metode ini diaplikasikan secara menyeluruh oleh banyak perusahaan didunia.

Rumus yang digunakan dalam mencari nilai OEE adalah sebagai berikut:

OEE $(\%)=\operatorname{Availability}(\%) \times$

Performance Effeciency $(\%) \times$

Quality Rate(\%)

Nakajima (1988), menyatakan pada pengukuran OOE terdapat 3 nilai utama, yaiitu :

\section{Availability Ratio}

Rumusan yang digunakan dalam mengukur availability adalah :

$$
\begin{aligned}
& \text { Availability }=\frac{\text { loading time }- \text { downtime }}{\text { Loading Time }} \times \\
& 100 \%
\end{aligned}
$$

Availability adalah rasio waktu operasional mesin yang tersedia terhadap loading timenya. Untuk menghitung availability mesin dibutuhkan nilai dari :

\section{a. Loading time \\ b. Downtime \\ c. Operation time}

Loading time adalah waktu yang tersedia (availability) per hari atau per bulan dikurang dengan waktu downtime mesin direncanakan (planned downtime).
Loading Time $=$ Total availability -

Planned downtime

Planned downtime adalah jumlah waktu downtime mesin untuk pemeliharaan (scheduled maintenance) atau kegiatan manajemen lainnya.

Formula penghitungannya adalah:

$$
\begin{array}{r}
\text { Downtime }=\text { Breakdown }+ \text { Set up } \quad(10) \\
\text { Operation Time }=\text { Loading time }- \text { Downtime }
\end{array}
$$

\section{Performance Efficiency}

Performance efficiency adalah rasio kuantitas produk yang dihasilkan dikaitkan dengan waktu siklus idealnya terhadap waktu yang tersedia untuk melakukan proses produksi (operation time).

Performance Efficiency $=$

$\frac{\text { processed Amount } \times \text { ideal cycle time }}{\text { Operation Time }} 100$

Ideal cycle adalah siklus waktu proses yang diharapkan dapat dicapai dalam keadaan optimal atau tidak menghalangi hambatan. Ideal cycle time pada mesin kneader merupakan waktu proses yang dapat dicapai mesin dalam proses produksi dalam keadaan optimal atau mesin tidak mengalami hambatan dalam memproduksi. Waktu optimal mesin kneader dalam sehari menghasilkan produk $150 \mathrm{~kg} / \mathrm{hari}$.

Rumus yang digunakan sebagai berikut:

waktu siklus ideal $=\frac{\text { loading time }}{\text { Total } \text { produksi }}$

\section{Quality Rate}

Quality rate adalah ratio produk yang baik (good product) yang sesuai dengan spesifikasi kualitas produk yang telah ditentukan terhadap jumlah produk yang diproses. Dalam perhitungan ratio Rate of Quality product ini, proses amount adalah Total Product Process sedangkan Defect Amount adalah Total Reject.

Rumusan yang digunakan adalah sebagai berikut : 
Quality Rate $=$

$\frac{\text { procces amount-defect amount }}{\text { Processed amount }} \times 100 \%$

\subsection{Pengumpulan Data}

Dalam mendapatkan data guna penyusunan penelitia ini, maka metode pengumpulan data dilakukan dengan :

\section{a. Observasi}

Merupakan metode dengan mengadakan pengamatan langsung pada objek yang diteliti. Yaitu melakukan pengamatan langsung mengenai sistem perawatan mesin di PT. XYZ.

\section{b. Studi Pustaka}

Merupakan metode perncarian data dari buku-buku, literatur maupun arisp dari datadata perusahaan di PT. XYZ.

\section{c. Wawancara (Interview)}

Merupakan metode percakapan langsung dengan sejumlah individu yang akan diwawancarai. Dalam hal ini penulis melakukan wawancara dengan operator produksi, operator teknisi maintenance, supervisor, foreman di PT. XYZ.

d. Merangkum data-data tentang hal yang berkaitan dengan penelitian.

Dalam penelitian ini adapun pengolahan data yang dilakukan yaitu dengan metode Overall Equipment Effectiveness, meliputi :

1. Perhitungan Availability

2. Perhitungan Performance Efficiency

3. Perhitungan Quality Rate

4. Perhitungan Overall Equipment Effectiveness

\section{HASIL DAN PEMBAHASAN}

Data yang digunakan adalah data pada periode Januari 2018 - Juni 2018 yaitu data waktu downtime, planned downtime, waktu set up, dan waktu produksi, dan data lain yang mendukung dalam pemecahan masalah.

\subsection{Data waktu downtime (breakdown)}

Kerusakan (breakdown) atau berhubungan dengan kegagalan.Jenis kegagalan meliputi fungsi stoping sporadic kegagalan dan fungsi mengurangi kegagalan dimana fungsi peralatan turun di bawah tingkat normal. Data waktu breakdown dapat dilihat pada Tabel 2 .

Tabel 2. Data Waktu Kerusakan (breakdown) Mesin Kneader

\begin{tabular}{cc}
\hline Bulan & Total Waktu Kerusakan \\
& (jam) \\
\hline Januari & 6 \\
\hline Februari & 8 \\
\hline Maret & 7 \\
\hline April & 10 \\
\hline Mei & 5 \\
\hline Juni & 4 \\
\hline
\end{tabular}

Sumber: Data Perusahaan (2018)

\subsection{Planned Downtime}

Merupakan waktu pemberhentian mesin yang telah ditetapkan, untuk waktu pemeliharaan (schedule maintenance) agar mesin tidak rusak saat proses produksi berlangsung, pemeliharaan dilakukan secara rutin dan terjadwal yang dibuat oleh departeman maintenance. Data waktu pemeliharaan dapat dilihat pada Tabel 3.

Tabel 3. Data Waktu Pemeliharaan Mesin Kneader

Bulan $\begin{gathered}\text { Total waktu } \\ \text { pemeliharaan }\end{gathered}$

(jam)

\begin{tabular}{ll}
\hline Januari & 12 \\
\hline
\end{tabular}
58 


\begin{tabular}{cc}
\hline Februari & 10 \\
\hline Maret & 9 \\
\hline April & 9 \\
\hline Mei & 15 \\
\hline Juni & 8
\end{tabular}

e) Total reject yaitu jumlah total yang ditolak karena cacat pada produk atau tidak sesuai dengan spesifikasi kualitas produk.

f) Total scrap yaitu jumlah total produk yang rusak atau sisa hasil proses.

Tabel 5 Data Produksi Mesin Kneader Periode Januari-Juni 2018

Sumber: Data Perusahaan (2018)

3.3 Data waktu set up

\begin{tabular}{|c|c|c|c|c|c|c|}
\hline Bln & $\begin{array}{l}\text { Total } \\
\text { available } \\
\text { time }\end{array}$ & $\begin{array}{c}\text { Total } \\
\text { produk } \\
\text { proses }\end{array}$ & $\begin{array}{l}\text { Total } \\
\text { good } \\
\text { produk }\end{array}$ & $\begin{array}{c}\text { Total } \\
\text { rejek } \\
(\mathrm{kg})\end{array}$ & $\begin{array}{c}\text { Total } \\
\text { scrap } \\
(\mathrm{kg})\end{array}$ & $\begin{array}{c}\text { Total } \\
\text { actual } \\
\text { (jam) }\end{array}$ \\
\hline
\end{tabular}

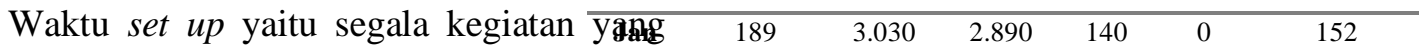
perlu dilakukan terhadap mesin sampai mesin
tersebut produktif menghasilkan produk bafk.

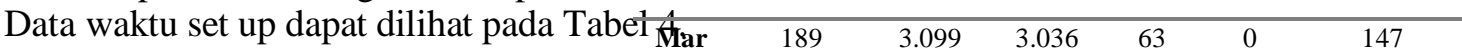

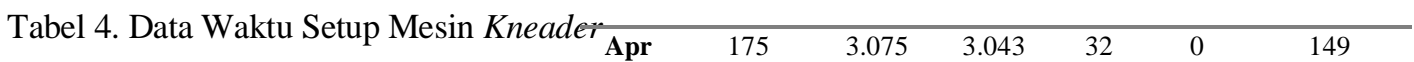

\begin{tabular}{cccccccccc}
\hline \multirow{2}{*}{$\begin{array}{c}\text { Bulan } \\
\text { Total waktu set up }\end{array}$} & & Mei & 189 & 3.022 & 2.995 & 27 & 0 & 147 \\
\cline { 4 - 8 } & (jam) & Jun & 182 & 3.015 & 3.002 & 13 & 0 & 147 \\
\hline
\end{tabular}

\begin{tabular}{cc}
\hline Januari & 4,1 \\
\hline Februari & 5,3 \\
\hline Maret & 4,2 \\
\hline April & 4 \\
\hline Mei & 6 \\
\hline Juni & 3,5
\end{tabular}

Sumber: Data Perusahaan (2018)

\subsection{Data produksi}

Data produksi mesin kneader di PT.XYZ dalam periode Januari 2018 - Juni 2018 yaitu:

a) Total available time adalah total waktu mesin yang tersedia untuk melakukan proses produksi dalam satuan jam.

b) Total product processes adalah jumlah total produk yang diproses oleh mesin dalam satuan jam.

c) Total good product adalah jumlah total produk yang baik dengan spesifikasi kualitas produk yang telah ditetapkan.

d) Total actual adalah total waktu operasi actual pada mesin.

\section{Perhitungan Availability}

Berdasarkan data yang ada maka availability pada bulan Januari 2018 dapat dihitung menggunakan persamaan (8).

$$
\begin{gathered}
\text { Availability }= \\
\frac{\text { loading time-downtime }}{\text { loading time }} \times 100 \% \\
\text { Loading time }=\text { Total availability time } \\
- \text { planned downtime }
\end{gathered}
$$

Downtim $=$ Loading time + set up

Operation time $=$ Loading time downtime

$$
\begin{array}{rlr}
\text { Loading time } & =189-12=177 \mathrm{jam} \\
\text { Downtime } & =6+4,1 \quad=10,1 \mathrm{jam} \\
\text { Operation time } & =177-10.1 \quad=166,9 \mathrm{jam} \\
& \text { Availability } \\
& =\frac{166,9}{177} \times 100 \%=94,29 \%
\end{array}
$$

Dengan perhitungan yang sama untuk menghitung availability, perhitungan dari 
Februari - Juni 2018 dapat dilihat pada Tabel 6.

Tabel 6 Availability mesin kneader Periode Januari 2018 - Juni 2018

\begin{tabular}{|c|c|c|c|c|}
\hline Bulan & $\begin{array}{c}\text { Total } \\
\text { loading } \\
\text { time } \\
\text { (jam) }\end{array}$ & $\begin{array}{l}\text { Total } \\
\text { Downt } \\
\text { ime } \\
\text { (jam) }\end{array}$ & $\begin{array}{c}\text { Total } \\
\text { Operation } \\
\text { time } \\
\text { (jam) }\end{array}$ & Availability \\
\hline Januari & 177 & 10,1 & 166,9 & 94,29 \\
\hline Februari & 158 & 13,3 & 144,7 & 91,58 \\
\hline Maret & 180 & 11,2 & 168,8 & 93,77 \\
\hline April & 166 & 14 & 152 & 91,56 \\
\hline Mei & 174 & 11 & 163 & 93,67 \\
\hline Juni & 174 & 7,5 & 166,5 & 95,68 \\
\hline
\end{tabular}

Sumber: Pengolahan Data (2019)

\section{Perhitungan Performance Efficiency}

Berdasarkan data yang ada maka performance efficiency pada bulan Januari 2018 dapat dihitung menggunakan persamaan (11).

$$
\begin{aligned}
& \text { Performance Efficiency } \\
& =\frac{\text { proses amount } x \text { cycle time }}{\text { operation time }} \times 100 \% \\
& \text { cycle time }=\frac{7 \mathrm{jam}}{150}=0,0466 \mathrm{jam} \\
& \text { Performance Efficiency } \\
& \begin{array}{l}
=\frac{3030 \times 0,0466}{166,9} \times 100 \% \\
=84,60 \%
\end{array}
\end{aligned}
$$

Dengan menggunakan perhitungan yang sama di atas untuk menghitung performance efficiency periode Februari 2018 - Juni 2018 dapat dilihat pada Tabel 7.

Tabel 7 Performance Efficiency mesin kneader periode Januari 2018 - Juni 2018

60

\begin{tabular}{ccccc}
\hline Bln & $\begin{array}{c}\text { Total } \\
\text { Produk } \\
\text { Proses }\end{array}$ & $\begin{array}{c}\text { Cycle } \\
\text { Time } \\
\text { (jam) }\end{array}$ & $\begin{array}{c}\text { Operating } \\
\text { Time }\end{array}$ & $\begin{array}{c}\text { Performance } \\
\text { Efficiency }\end{array}$ \\
\cline { 4 - 5 } & $(\mathrm{kg})$ & & $($ jam $)$ & $(\%)$ \\
\cline { 4 - 5 } Jan & 3.030 & 0,0466 & 166,9 & 84,6 \\
\hline Feb & 3.042 & 0,0466 & 144,7 & 97,96 \\
\hline Mar & 3.099 & 0,0466 & 168,8 & 85,55 \\
\hline Apr & 3.075 & 0,0466 & 152 & 94,27 \\
\hline Mei & 3.022 & 0,0466 & 163 & 86,39 \\
\hline Jun & 3.015 & 0,0466 & 166,5 & 84,38 \\
\hline
\end{tabular}

Sumber: Pengolahan Data (2019)

\section{Perhitungan Quality Rate}

Berdasarkan data yang ada maka quality rate pada bulan Januari 2018 dapat dihitung menggunakan persamaan (13).

$$
\begin{aligned}
& \begin{array}{l}
\text { Quality Rate } \\
\text { procces amount }- \text { defect amount }
\end{array} \\
& \begin{array}{c}
\text { procces amount } \\
\text { Quality Rate }= \\
=\frac{3030-140}{3030} \times 100 \% \\
=95,37 \%
\end{array}
\end{aligned}
$$

Dengan menggunakan perhitungan yang sama untuk menghitung Quality Rate dari periode Februari 2018 - Juni 2018 dapat dilihat pada Tabel 8.

Tabel 8 Perhitungan Quality Rate Periode Januari 2018 - Juni 2018

\begin{tabular}{cccc}
\hline Bulan & $\begin{array}{c}\text { Total } \\
\text { Produk } \\
\text { Proses }\end{array}$ & $\begin{array}{c}\text { Total } \\
\text { Reject } \\
(\mathrm{kg})\end{array}$ & $\begin{array}{c}\text { Quality } \\
\text { Rate } \\
(\%)\end{array}$ \\
\cline { 2 - 2 } & & & \\
& & & \\
\hline Januari & 3.030 & 140 & 95,37 \\
\hline Februari & 3.042 & 42 & 98,61 \\
\hline Maret & 3.099 & 63 & 97,96 \\
\hline
\end{tabular}

Analisis Penerapan Total Productive Maintenance (TPM) dengan Metode Overall Equipment Effectiveness (OEE) pada Mesin Kneader (Studi Kasus PT.XYZ) 


\begin{tabular}{cccc}
\hline April & 3.075 & 32 & 98,95 \\
\hline Mei & 3.022 & 27 & 99,16 \\
\hline Juni & 3.015 & 13 & 99,56
\end{tabular}

Sumber: Pengolahan Data (2019)

\section{Perhitungan Nilai Overall Equipment Effectiveness (OEE)}

Setelah nilai Availability, Performance Efficiency, Quality Rate diperoleh maka dilakukan perhitungan nilai overall equipment efficiency (OEE) untuk mengetahui besarnya efektifitas penggunaan mesin. Perhitungan OEE merupakan perkalian nilai-nilai Availability, Performance Efficiency, Quality rate yang sudah didapat.

Berdasarkan data yang ada maka OEE pada bulan Januari 2018 dapat dihitung menggunakan persamaan (7).

$$
\begin{aligned}
O E E & =(0,942 \times 0,846 \times 0,953) \times 100 \% \\
& =75,94 \%
\end{aligned}
$$

Dengan menggunakan perhitungan yang sama, maka nilai OEE periode Februari 2018 - Juni 2018 dapat dilihat pada Tabel 9

Tabel 9 Perhitungan Overall Equipment Effectiveness (OEE) pada periode Januari - Juni

\begin{tabular}{|c|c|c|c|c|}
\hline & $\begin{array}{c}\text { Availa } \\
\text { bility }\end{array}$ & $\begin{array}{c}\text { Perfor- } \\
\text { mance } \\
\text { Efficiency }\end{array}$ & $\begin{array}{c}\text { Quality } \\
\text { Rate }\end{array}$ & \\
\hline Bln & $(\%)$ & $(\%)$ & $(\%)$ & OEE $(\%)$ \\
\hline Jan & 94,29 & 84,6 & 95,37 & 75,94 \\
\hline Feb & 91,58 & 97,96 & 98,61 & 88,32 \\
\hline Mar & 93,77 & 85,55 & 97,96 & 78,43 \\
\hline Apr & 91,56 & 94,27 & 98,95 & 85,24 \\
\hline Mei & 93,67 & 86,39 & 99,1 & 80.04 \\
\hline Jun & 95,68 & 84,38 & 99,56 & 80,18 \\
\hline Rata-rata & & & & 81,62 \\
\hline
\end{tabular}
2018
Sumber: Pengolahan Data (2019)

Dari hasil perhitungan nilai rata-rata Overall Equipment Effectiveness (OEE) diperoleh $81,62 \%$, sedangkan standar dunia yaitu $85 \%$. Oleh karena itu perlu adanya improvement sesegera mungkin.

\section{Time Losses Dari Six Big Losses}

Dari data six big losses didapatkan hasil time losses dapat disebabkan karena kerugian kegagalan peralatan, kerugian setup dan penyesuaian, kerugian idling dan penghentian minor, mengurangi kehilangan kecepatan, mengolah kembali, skrap dapat dilihat hasil perhitungan ke enam sumber time losses pada tabel berikut :

Tabel 10. Six Big Losses

\begin{tabular}{|c|c|c|c|}
\hline Six Big Losses & $\begin{array}{c}\text { Total } \\
\text { Time } \\
\text { Losses } \\
\text { (jam) }\end{array}$ & Persentase & $\begin{array}{c}\text { Kumulatif } \\
(\boldsymbol{\%})\end{array}$ \\
\hline $\begin{array}{c}\text { Reduce Speed } \\
\text { Losses }\end{array}$ & 109,84 & 42,66 & $42,66 \%$ \\
\hline $\begin{array}{c}\text { Idling and Minor } \\
\text { Stoppages Losses }\end{array}$ & 80,5 & 31,26 & $73,92 \%$ \\
\hline $\begin{array}{c}\text { Equipment Failure } \\
\text { Losses }\end{array}$ & 40 & 15,56 & $89,48 \%$ \\
\hline $\begin{array}{c}\text { Set Up and } \\
\text { Adjusment Losses }\end{array}$ & 27,1 & 10,52 & $100,00 \%$ \\
\hline $\begin{array}{c}\text { Rework Losses } \\
\text { Yield/ Scrap } \\
\text { Losses }\end{array}$ & 0 & 0 & $100,00 \%$ \\
\hline
\end{tabular}

Sumber: Pengolahan Data (2019)

Dari tabel di atas, Six big losses yang paling tinggi adalah Reduce speed losses 109,84 jam, Idling and minor stoppages losses 80,5 jam, Equipment failure losses $40 \mathrm{jam}$, Set up and adjustment losses 27,1 jam, Rework Losses 0 jam, Yield / Scrap Losses 0 jam. Secara kumulatif dari tabel di atas dapat diketahui persentase time losses yang paling besar adalah reduced speed losses $42,66 \%$ dan idling and minor stoppages losses $73,92 \%$. Reduce speed losses disebabkan karena mesin berjalan lebih lambat dari waktu idealnya. Sedangkan idling and minor stoppages losses 
disebabkan karena mesin berhenti secara berulang-ulang

\section{Diagram Sebab Akibat}

Penentuan sebab akibat dicari menggunakan fishbone diagram atau diagram sebab akibat sehingga diagram fishbone ini dapat ditentukan langkah-langkah preventive maintenance yang tepat sesuai dengan masalah yang dihadapi oleh perusahaan. Hasil analisa terhadap faktor yang memberikan kontribusi terbesar penyebab rendahnya efektivitas mesin kneader pada diagram sebab akibat didapat dari hasil penulis membentuk sebuah tim untuk memberikan saran dan masukan untuk perbaikan. Hasil analisa dengan diagram fisbone dapat ditunjukkan pada gambar 1 dan gambar 2

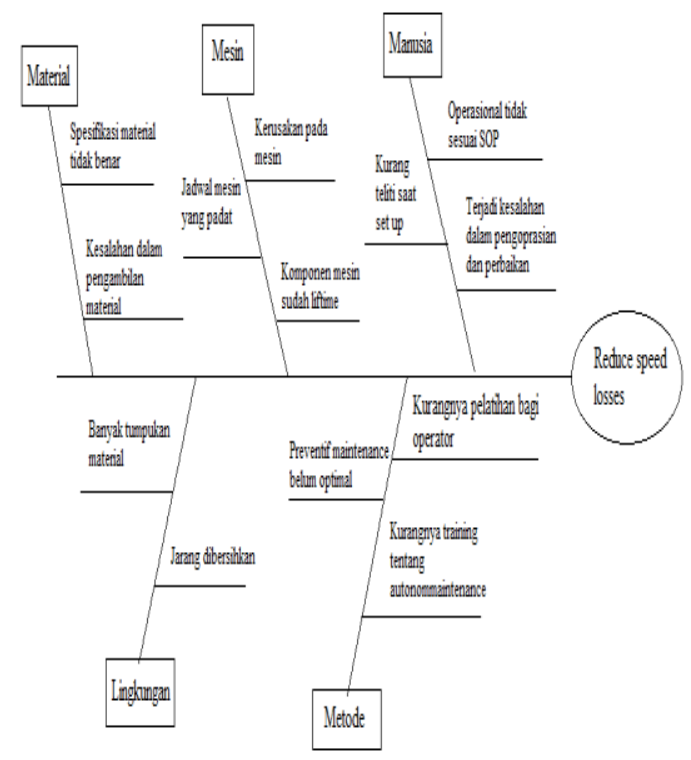

Sumber: Pengolahan Data (2019)

Gambar 1 Diagram fishbone Reduce Speed Losses

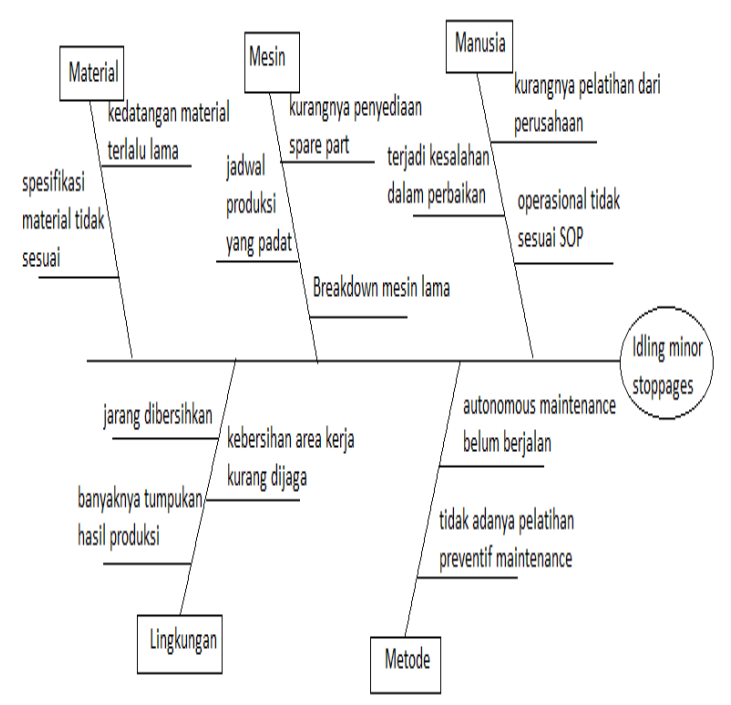

Sumber: Pengolahan Data (2019)

Gambar 2 Diagram Fishbone Idling and minor stoppages losses

\subsection{Usulan Perbaikan}

Setelah mengetahui penyebab dan faktor yang menghambat proses produksi maka peneliti ingin memberikan usulan perbaikan / saran untuk perusahaan agar melakukan improvement sehingga dapat meningkatkan efektivitas mesin kneader dan melancarkan proses produksi.

Hasil usulannya sebagai berikut :

1) Perusahaan harus lebih ketat lagi terhadap perekrutan pekerja, setelah itu memberikan training dan pelatihan tentang pengoprasian mesin dan cara perawatannya agar lebih siap saat bekerja di lapangan. Memberikan pengetahuan tentang checkseet dan SOP sebagain dasar untuk mengoprasikan mesin dengan benar sehingga operator tau apabila ada yang tidak normal pada mesin tersebut.

2) Perusahaan harus memberikan layout di sekitar area mesin agar tidak ada bahan baku/material lain di area mesin selain bahan baku yang akan di proses. Perusahaan harus memberikan arahan

62 
untuk kebersihan area kerja sebelum dan sesudah bekerja, agar tercipta kondisi nyaman dan aman saat bekerja. Pembuatan layout untuk barang yang menunggu antrian untuk diproses agar tidak menumpuk di area mesin agar tempat kerja menjadi lega dan bisa bergerak dengan leluasa.

3) Menentukan standar perawatan yang baik sesuai dengan manual book yang terlebih dahulu ditentukan oleh bagian maintenance atau teknisi. Memaksimalkan sistemasi yang sudah berjalan

\section{KESIMPULAN DAN SARAN}

\section{Kesimpulan}

Berdasarkan hasil analisa dan hasil perhitungan dengan menggunakan metode OEE (Overall Equipment Effectiveness) dan Six Big Losses pada mesin kneader, dapat diambil beberapa kesimpulan yaitu :

1. Rata-rata hasil perhitungan Overall Equipment Effectiveness mesin kneader saat ini yaitu sebesar $81,62 \%$. Nilai ini masih dibawah standar dunia yaitu $85 \%$. Berdasarkan nilai tersebut dikaji apa saja yang menjadi penyebab menurunnya efektivitas mesin kneader.

2. Faktor terbesar total time losses yang menyebabkan menurunnya efektivitas mesin kneader melalui pengukuran six big losses adalah reduce speed losses dan idling and minor stoppages losses. Reduce speed losses merupakan losses terbesar dari keseluruhan losses yang terjadi yaitu $42,66 \%$ dan idling and minor stoppages losses ditempat kedua dengan nilai $31,27 \%$, dan berikutnya Equipment Failure Losses dengan nilai $15,54 \%$.

3. Untuk meningkatkan efektivitas mesin kneader, operator sebaiknya diberikan pengetahuan skill tentang tanda-tanda kerusakan yang mungkin akan terjadi khususnya pada mesin kneader. Sehingga apabila muncul tanda-tanda tersebut operator bisa langsung melaporkan kepada bagian maintenance untuk ditindak lanjuti. Selain itu operator juga diberikan tugas tambahan untuk melakukan perawatan terhadap peralatan yang bisa digunakan dalam proses produksi sehingga pekerjaan bagian maintenance bisa lebih berfokus pada masalah yang lebih diutamakan.

\section{Saran}

Dari hasil penelitian ini dapat diberikan saran yaitu sebagai berikut:

Perusahaan memerlukan pelatihanpelatihan untuk menambah wawasan para operator tentang tata cara pemeliharaan mesin yang baik, agar kerusakan pada mesin akibat kesalahan operator atau manusia dapat dimaksimalkan. Bagian pemeliharaan selaku penanggung jawab kerusakan dan perbaikan mesin, hendaknya harus terus mengawasi jalannya aktivitas pemeliharaan yang dilaksanakan oleh operator mesin, sehingga tidak terjadi kesalahan prosedur pemeliharaan yang dapat menyebabkan kerusakan yang cukup besar. Perusahaan harus menerapkan autonomous maintenance adalah salah satu prinsip dalam lean yang fokus pada improvement mesin, untuk mecegah terjadinya mesin berhenti dan mencegah kerusakan mesin yang lebih lama.

\section{DAFTAR PUSTAKA}

Assauri, Sofyan.2008. Manajemen dan Operasi. Edisi Revisi LPFEUI. Jakarta

Ali, Muhammad.2013. Penelitian Pendidikan dan Strategi. Angkasa.

Anshori, N. dan Mustajib, M. I. 2013. Sistem Perawatan terpadu (Integrated Maintenance System), Yogyakarta : Graha Ilmu.

Corder, Anthony, dan Kusnul Hadi. 1988. Manajemen Pemeliharaan Teknik. Jakarta: Erlangga.

Heizer, Jay, dan Barry Render. 2001. Operation Manajement. $6^{\text {th }}$ edition. New Jersey: Prentice Hall Inc.

Mulyadi, 2001. Sistem Akutansi Edisi Tiga. Jakarta: Salemba Empat.

Mukhril. 2014. Penerapan Pada Industri Total Productive Maintenance Dan Total Quality Management. Tanggerang: Mega Karya.

Nakajima, Seiichi. 1988. Introduction to Total Productive Maintenance (TPM). Cambridge: Productivity Press Inc. 
Submitted: 16/04/2020; Revised: 05/05/2020; Accepted: 08/06/2020; Published: 29/06/2020

Suzuki, Tokutaro. 1992. TPM in Process Industries. Japan: Japan Institute of Plant Maintenance pada Mesin Kneader (Studi Kasus PT.XYZ) 